\title{
Network Code on Requirements for Generators - a Discussion. Resynchronizing with paradigm shifts
}

\author{
Mihai Sanduleac, Lucian Toma \\ Faculty of Power Engineering \\ University Politehnica of Bucharest \\ Bucharest, Romania \\ mihai.sanduleac@upb.ro \\ lucian.toma@upb.ro
}

\author{
Gianfranco Chicco \\ Dipartimento Energia "Galileo Ferraris" \\ Politecnico di Torino \\ Torino, Italy \\ gianfranco.chicco@polito.it
}

\author{
Mihaela Albu \\ Faculty of Electrical Engineering \\ University Politehnica of Bucharest \\ Bucharest, Romania \\ albu@ieee.org
}

\begin{abstract}
The Network Code on Requirements for Generators, known also as RfG, is the most recent document approved by the European Commission that recommends the technical conditions for connection and operation of all types of generators in the ENTSO-E zone. Although RfG was published in the Official EU Journal in 2016, each EU member country is responsible to adopt it in the form that best suits to its characteristics. Therefore, the latest achievements in deployment of storage and renewables technologies should be also considered. Moreover, the new concepts included in the $\mathrm{EU}$ winter package (2016) for empowering the citizen and encouraging prosumer's self-consumption, resilience and efficiency requires careful analysis of the document. This paper aims at identifying some shortcomings of the proposed document, based on latest technology advancements and societal aspirations, and proposes a new approach that allows synchronizing the new network codes with the smart grids paradigm shift.
\end{abstract}

Index Terms-generators, network code, storage, ancillary services, hierarchy control, renewable energy sources (RES)

\section{INTRODUCTION}

The Network Code on Requirements for Generators [1], known also as $R f G$, is the latest approved document for clarifying the technical conditions for connecting and operation the generator in the ENTSO-E zone. Even if it is very new and now still in process to be approved and adapted with specificity of the EU countries, the latest achievements in storage and renewables technologies, but also the new concepts of the EU Winter package [2] needs reconsideration of this norm. Most of the advanced technologies reached a good level of maturity during the long process of RfG approval, including the comitology, while the lack of communication and inefficient procedures for public debates made impossible the necessary amendments, finally failing in supporting the awareness of paradigm shift, thus acting as an iceberg of technology advancement. This paper is intended to show how much of this iceberg of technology is now threatening some important aspects of RfG and provides solutions to be implemented during the national code adopting procedure, to be finalized in 2018 .

The paper is addressing only some of the RfG drawbacks. Other aspects may be subject of other studies.

\section{GAME CHANGERS}

The most important shortcomings that need responsible analysis and amendment during the national adoption are listed as follows:

a) Advancement towards high penetration of renewables: today, in good meteorological conditions, the share of generation from Renewable Energy Sources (RES) can reach up to $100 \%$ in the energy mix of several countries for longer periods of time. Additionally, the market signals show dramatic price decrease for photovoltaic panels, which makes them ubiquitous and adequate for massive distribution. For instance, in [3], photovoltaics were estimated at around $1600 € / \mathrm{kW}$ installed, while the actual investment are down to half costs. Moreover, the latest results of international bids show that Power Purchase Agreements (PPA) business models are based on prices for grid-connected RES down to $2.42 \varnothing / \mathrm{kWh}$ in power purchase contracts (PPC) framework [4], which makes PV or wind energy the cheapest electricity generation, though a couple of years ago it was still expensive and needing subsidies.

b) Electrical energy storage is not considered: presently storage units are capable of providing support for peak power shaving. The actual market signals provide however enough reasons to believe that battery storage is "knocking at the door" to enable smart grid deployment. The Tesla's announcement related to the construction of the Gigafactory 1 that will be fully operational in 2018, producing storage units with prices as low as $350 \$ / \mathrm{kWh}$ (possibly already to be reached in 2017), is the spark that changes the vision on the future smart grids, centered on the prosumer accommodating RES paired with storage. One can read the code [1] either in terms of "storage is not forbidden but it needs (maybe) another code", or "that the storage is treated as in RfG, when being in generator mode". The first option leaves TSOs, DSOs and end-users without a connection code for a technology which is booming, the second option handles generation and storage-during-generation-mode as separate entities, and does not take advantage of the synergetic combination.

c) Some ancillary services are considered to be provided strictly by generation units (e.g. primary frequency reserve by 
type $\mathrm{C}$ generators, Article 15, 2, (d), frequency sensitive mode FSM, also described in table 4 and figure 5, supporting classic FCR if the deadband is zero), named in RfG "power generating modules"; however, advancements in the storage technology made recently possible in the UK to award the $182 \mathrm{MW}$ of the needed frequency containment reserve (FCR) service to storage systems only [5]. Batteries providing FCR are studied, e.g. in [6]. In [7] the service is reported to be provided for the German FCR market by using distributed battery storage resources from households with installed roof-top PV plants. This possible redirection of the service to storage resources alone directly affects the RfG requirements which presently include also RES (connected to the system through "power park modules"); these units should be able to provide ancillary services despite of the energy losses for keeping headroom in production, instead of transferring such requirement to the storage systems which can provide services without this drawback. A technical realization, to accept FCR implemented by storage resources for pairing and covering the requirements asked for the RES of type $\mathrm{C}$ is however subject to interpretation and not a clear possibility, as it should be for avoiding too strict implementations.

d) The need for specific performances in terms of synthetic inertia following the reduction of natural (mechanical) inertia is not clearly defined: this may impose different resources than the already mentioned RES headroom and adapted automation schemes.

e) The Winter package [2] brings important changes to the energy policy, among which one can highlight "placing the citizen in the center and energy efficiency". This is in contradiction with the requirement [1] for A type generators that are assumed to be directly controllable even in case of sizes down to $800 \mathrm{~W}$, instead of asking for fair conditions at the connection point. This may severely affect the prosumer's ecosystem, as a part of citizen empowerment and resilience.

f) $100 \% \mathrm{CO}_{2}$ free energy in 2050, most of it from renewables, is the new aim of the European Commission, which can boost the number of prosumers and new ways of ensuring the system functionality, in hierarchies much different than a centralized approach.

g) Cyber security became more and more important, after new cyber-attacks such as the one in Ukraine [9]. This is a tangible prove that highly concentrated control solutions, such as the availability for controlling the set-point of the generation resource at all network levels by the system operators, are increasing the cyber-attack threats due to the high impact of potential attacks such as the unintended curtailment of a large number of generators. On the opposite side, resilient prosumers should and can be protected against cyber-attacks, due to their increased autonomy, e.g. a limited power injection condition may be implemented as a local automation, not needing remote curtailment orders; the limitations can be solved internally based on the prosumer ecosystem [12], i.e. independently of the external power system conditions of operation, as agreed with the DSO for example in the form of connection conditions for.

h) Smart metering rollouts are not considered. AMI is an important technological driver, and the net-metering and near real-time observability are essential features. One can use smart meters for further integration in traditional SCADA, overcoming additional and costly communication channels which might be blocking factors for further RES-based generators deployment.

i) Smart Grid functionalities are underestimated. The efficient multi-level power control together with the ICT solutions, studied and demonstrated for more than 10 years, should be appropriately reflected. For instance, microgrid efficient control is substituted by enabling complete control of relevant network operator. There is no tradeoff with possible automation, local balancing feature, but only access to full control from DSO.

Some of these aspects are addressed in the following section.

\section{SOME DRAWBACKS OF RFG}

\section{A. Storage technology neglected, even when becomes essential}

Article 3 from RfG, "Scope of Application", point 2b, stipulates that the Regulation does not apply to storage devices (other than pump storage). This is an important undervalue of a technology which is essential for the energy generation in the near future. As a recent example, we can mention the $280 \mathrm{MWh}$ $(80 \mathrm{MWh}+120 \mathrm{MWh}+80 \mathrm{MWh})$ of Li-Ion storage commissioned in January-February 2017 in California, as first step for reaching 1.3 GW goal of storage in 2020 [8], while Europe is still lagging with much smaller pilots. This storage facility is used to phase-out gas power plants for peak hours in the CAISO grid, by providing $70 \mathrm{MW}$ power during 4 peak hours, which makes storage for the first time a player in the mix of energy production. In addition, we mention also the South Australia case, where peak-load problems may be solved by producing $100 \mathrm{MW}$ for three hours, from pump storage and/or Li-Ion storage. Factories like Tesla's Gigafactory 1, that will be ready to produce up to $35 \mathrm{GWh} /$ year from storage, show that storage is stepping on a mature phase, with high opportunities expected in the near future. These aspects are showing that production based on storage needs to be part of the RfG content, as an important technology has not to be neglected.

In [11] it is stated that "A blanket requirement for inertial response may prove punitive for some technologies (e.g. this is very difficult and expensive for PV), and should be avoided" (page 94) and that "Design of market mechanisms to assure adequate frequency response should include features to allow provision of frequency response by energy storage devices with finite (limited) energy ratings" (page 95). This gives also the signal that RES production units need to be supported by storage technologies for ancillary services duties, rather than making them operating in an inefficient way.

\section{B. Cyber security - between highly centralized and partially decentralized}

The RfG document includes a large number of stipulations that allow controlling a generator's output either by the DSO or by the TSO, eventually after aggregation borne to the DSO. The cyber-security is highly overlooked, meaning that breach in data security may bring high and unacceptable vulnerabilities. For this reason, it is more desirable that the control of some 
functionalities is transferred to the prosumer. This can dramatically improve the cyber-resilience, as the different systems are loosely coupled and can live with a certain independency, even when some parts of the smart grid or the total EMS/DMS-SCADA system are compromised. It is a sort of compartmentalization of the ICT solution, which brings much higher resilience and better ways to mitigate cyber-threats.

\section{No specification about prosumer.}

The prosumer, defined by self-generation and selfconsumption (improved by local storage) operated as one entity is not addressed. Therefore, one of the main pillars of the EU policy is completely neglected.

Production behind the meter is not clearly presented in RfG. Because of lack of clarity on the subject, various interpretations have been collected from specialists, some of them stating that it is part of RfG scope, even if the production can be controlled locally for achieving local prosumer goals, thus not being subject to potential grid control.

$\mathrm{RfG}$ is keen that such production facilities may endanger the grid stability. However, in order to mitigate difficulty of controlling millions of power injection nodes in the grid, there are already solutions when either the power injected back is limited (e.g. $16 \mathrm{~A}$ in UK for roof PV), or when it is always set to zero exchange (the prosumer shall act as an independent power producer, with the extensive support of batteries) - the so called "zeroing out" supported by automation of usually called hybrid inverters.

None of these solutions are considered in RfG. In this respect, the controlling input for curtailment or even for full switching-off of the generation unit can act unnecessary similar to a "big brother" not interested in the local goals, autoconsumption and increased efficiency of the energy used at the place of production.

The absence of the prosumer case for the RfG document is a strong argument for calling into question the grid connection requirements, if local automation mitigates the grid stability through controlled injection for power in the grid.

\section{Generation specificity - essential but lost aspect}

There is an important aspect that can improve the RfG code systematization. The actual RfG specifies that the generators are of only two types: synchronous and power park generators, the latest being the ones which use static converters as an interface to the network. It is an over simplification in the new domain of power-park generation, which needs to be more detailed.

Table I gives our proposal for the generators matrix. In this table, in addition to the classification of the generators based on maximum active power, which organizes them into types $A$ to $\mathrm{D}$, the generation units need to be also classified based on their capacity of energy generation, a feature which is related to the technology. Table I shows the proposed types based on energy availability, where power-park modules are also split based on the power generation type:

G1 - classical generators (synchronous machines), which have enough fuel for a period $T_{B}$, such as one hour (the usual commercial time interval), and therefore there are no constraints (in energy terms) associated. In the actual RfG, they are also defined as "synchronous park generation modules" (Article 2, definition (9) in RfG).

G2 - generators for which the power output depends on environmental factors, is rapidly changing, and cannot be influenced by the facility owner. In this category, there are RESbased generation such as solar and wind. These generators have therefore limited extra energy contribution which depends not only on intermittent environmental conditions but also on power park (inverter) capability.

G3 - electrical energy storage resources with bivalent function: act as generators when operating in discharging mode and as consumers when operating in charging mode. Due to the characteristic of energy conservation, these are much different from the types G1 and G2, which do not have an energy cycle:

$$
E_{\text {storg_gen_to_grid }}=E_{\text {storg_cons_from_grid }}-E_{\text {Loss_storg }}
$$

Unofficial statements of some specialists suggest considering the storage systems in the RfG requirements when they operate in discharging mode and produce energy (situation which is even not accepted in today RfG, as stated in Article 3, $2 \mathrm{~d}$ ), and in the consumption code requirements when they operate in charging mode and absorbs power from the grid. This hides important features and potentials of the storage technology. For instance, a battery system attached to a PV plant consumes energy from the plant based on optimization strategy.

G4 - hybrid, which are either with RES behind the meter and consumption or up to more complex hybrid system, which have one bidirectional inverter connection and RES + storage embedded in the inverter logics.

$$
\begin{gathered}
E_{g e n \_t o \_g r i d}=E_{\text {storg_cons_from_grid }}-E_{\text {Loss_storg }}+E_{R E S_{-} u s e r} \\
-E_{\text {cons_user }}
\end{gathered}
$$

Table I presents the matrix of Power and Production specific technologies, as a modern and structured way of making RfG more functional. The split of type A in A1 and A2 is presented in the next proposed aspect. The table proposes different

\begin{tabular}{|c|c|c|c|c|c|}
\hline \multicolumn{2}{|r|}{ Type } & \multicolumn{4}{|c|}{ Generation unit (based on energy availability) $\downarrow$} \\
\hline Type & $\begin{array}{c}\text { Power } \\
\downarrow\end{array}$ & $\begin{array}{c}\text { G1 }=\text { classical } \\
\text { (all, except } \\
G 2, G 3, G 4)\end{array}$ & $\begin{array}{c}G 2= \\
\text { Intermittent } \\
(R E S)\end{array}$ & $\begin{array}{c}\text { G3 }= \\
\text { Storage } \\
\text { (bivalent) }\end{array}$ & $\begin{array}{c}\text { G4 }= \\
\text { Hybrid }\end{array}$ \\
\hline A1 & $\begin{array}{l}0.8 \mathrm{~kW}- \\
10 / 30 \mathrm{~kW} \\
\text { or } 100 \mathrm{~kW}\end{array}$ & $\operatorname{Req}(\mathrm{G} 1, \mathrm{~A} 1)$ & $\begin{array}{c}\text { Req } \\
(\mathrm{G} 2, \mathrm{~A} 1)\end{array}$ & $\begin{array}{c}\text { Req } \\
(\mathrm{G} 2, \mathrm{~A} 1)\end{array}$ & $\begin{array}{c}\text { Req } \\
(\mathrm{G} 4, \mathrm{~A} 1)\end{array}$ \\
\hline A2 & $\begin{array}{l}10 / 30 \text { or } \\
100 \mathrm{~kW}-1 \\
\mathrm{MW}\end{array}$ & $\operatorname{Req}(\mathrm{G} 1, \mathrm{~A} 2)$ & $\begin{array}{c}\text { Req } \\
(\mathrm{G} 2, \mathrm{~A} 2)\end{array}$ & $\begin{array}{c}\text { Req } \\
(\mathrm{G} 2, \mathrm{~A} 2)\end{array}$ & $\begin{array}{c}\text { Req } \\
(\mathrm{G} 4, \mathrm{~A} 2)\end{array}$ \\
\hline B & $1-5 \mathrm{MW}$ & $\operatorname{Req}(\mathrm{G} 1, \mathrm{~B})$ & $\begin{array}{c}\text { Req } \\
(\mathrm{G} 2, \mathrm{~B})\end{array}$ & $\begin{array}{c}\text { Req } \\
(\mathrm{G} 2, \mathrm{~B})\end{array}$ & $\begin{array}{c}\text { Req } \\
(\mathrm{G} 4, \mathrm{~B})\end{array}$ \\
\hline C & $5-20 \mathrm{MW}$ & Req(G1,C) & $\begin{array}{c}\text { Req } \\
(\mathrm{G} 2, \mathrm{C})\end{array}$ & $\begin{array}{c}\text { Req } \\
(\mathrm{G} 2, \mathrm{C})\end{array}$ & $\begin{array}{c}\text { Req } \\
(\mathrm{G} 4, \mathrm{C})\end{array}$ \\
\hline $\mathrm{D}$ & $>20 \mathrm{MW}$ & $\operatorname{Req}(\mathrm{G} 1, \mathrm{D})$ & $\begin{array}{c}\text { Req } \\
(\mathrm{G} 2, \mathrm{D})\end{array}$ & $\begin{array}{c}\text { Req } \\
(\mathrm{G} 2, \mathrm{D})\end{array}$ & $\begin{array}{c}\text { Req } \\
(\mathrm{G} 4, \mathrm{D})\end{array}$ \\
\hline
\end{tabular}
requirements (Req) for each cell/box in the matrix.

TABLE I. RFG RE-ORGANISATION MATRIX

E. Generation type A-loosing most of smart grid essentials

Another improvement that we consider as necessary is in the A type of generators, as also presented in Table I. 
According to RfG, all generators with rated power between $800 \mathrm{~W}$ and $1 \mathrm{MW}$ need to respect the same grid connection conditions. This is a major issue, because exactly in this region there is the most of the "smart grid" functionality. By treating them as a whole, important aspects are lost or superficially considered. We are pointing that most of the end-customers which will become in near future "empowered citizen", able to participate at the energy markets, are connected at low voltage with contractual power under $10 \mathrm{~kW}$ for single-phase connections and under $30 \mathrm{~kW}$ for three-phase connections. For these users, it is likely that the production will be integrated into prosumer internal networks, which are synchronous but behind the meter, allowing different efficiency measures, which can be also easily checked by the DSO through the smart meters (acting as net meters as well).

It is stringent for these behind the meter production facilities to be treated with options of partial or total self-consumption, based on automations which can be easily implemented on the prosumer site; such solution bring no harm to the network, but help to stability instead, given the full controllability even when the RES-based production is stochastic within the prosumer network.

As a conclusion, it can be noted that the actual RfG unification of all these generation technologies - very different in nature - transforms the energy ecosystem into a Procustean bed, where the mythological person was "curtailing" or enlarging the length of the laid people according to the bed dimensions. In a same manner - without considering the natural technical characteristics of the generation units, all resources in RfG are harmfully brought to the unique, inflexible and inefficient bed. With the matrix based on generation type G1-G4 one can propose solutions to improve the RfG concept, while keeping or even improving the system security.

For addressing the prosumer's functionality, we propose the following improvements, also reflected in Table I:

- Type A1, for grid connected power of up to $10 \mathrm{~kW} / 30 \mathrm{~kW}$ for single-phase / three-phase connection, in order to allow that roof-PV or other hybrid solutions can be organized without complex procedures and obligations. Here it may be proposed by relevant grid operator to have automations for limiting the output power to a certain value, e.g. 16 A (UK) or down to zero (Spain) [12]. The verification of this behavior is simple, to be provided, for example, by smart meters as they already have net metering feature included, and they do not need "big brother" control input nor (DSO-) SCADA integration; this type is considered the most important for smart grids deployments. In case of intelligent buildings or small commercial/industrial (CI) areas opting for internal ecosystems, the upper limit may increase e.g. to $100 \mathrm{~kW}$, with similar automation to avoid uncontrolled back injection.

- Type A2, which corresponds to classical generation units connected directly to LV, with $\mathrm{P}<1 \mathrm{MW}$, should be labeled as LV bulk production; the lower limit needs to be increased such that it goes outside a usual prosumer production facility, from $10 / 30 \mathrm{~kW}$ (or upper $100 \mathrm{~kW}$ limit for intelligent buildings or $\mathrm{CI}$ areas) up to $1 \mathrm{MW}$, by still respecting the RfG approach.

\section{FREQUENCY RELATED SUPPORT - RES FORCED TO INEFFICIENT PRODUCTION}

Since all generators are alike in RfG for a certain power range - except the synchronous / power park connection, an important aspect is also neglected: the fact that RES-based generation is not always suitable for delivering frequency services such as frequency containment reserve without degradation of efficiency and uncertainty. Frequency response is an increasingly important aspect studied in countries or regions with high RES penetration [10].

According to [11], there is a hierarchy of the load-frequency control, also depicted in Fig. 1.

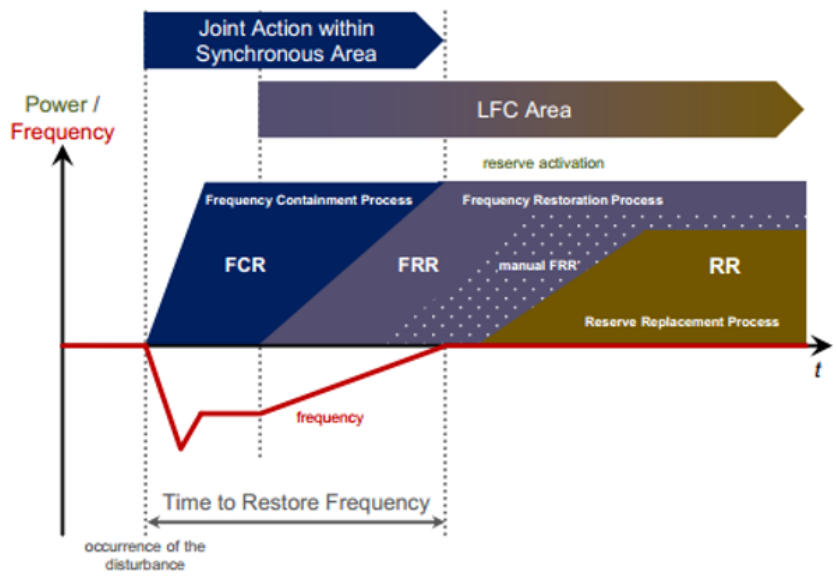

Fig. 1. Dynamic Hierarchy of Load-Frequency control [11].

Generators of type $\mathrm{C}$ and $\mathrm{D}$ are proposed in $\mathrm{RfG}$ to participate in FCR through the so called "frequency sensitive mode" (FSM). If these generators are RES-based (category neglected in RfG, but proposed for a new systematization in our paper), they need to be able to generate a lower power than the "maximum power" given by the environment (to keep a provision of active power frequency response, according to Article 5(c)(i) for type C). It means that even if a $\mathrm{PV}$ can produce $100 \mathrm{MW}$ of power at a certain time instant, it is requested that the generation set-point is set to $99 \mathrm{MW}$, in order to maintain a power reserve of $1 \mathrm{MW}$ ( $1 \%$ FCR service), sometime cited as being the so-called "headroom". As such units are dependent on the meteorological conditions, the $1 \%$ reserve may become uncertain when sudden variation of the meteorological conditions overlap large power unbalances.

PVs are usually working by implementing in the inverters' automation an improvement named Maximum Power Point Tracking (MPPT), which usually is searching physically for the maximum power extraction from PV (best efficiency) by testing parameters allowing operation near to the actual state, an activity which is named "tracking". About $1 \%$ of the production is lost all the time, but due to the difficulty of turning from MPPT to power-controlled automation, the real losses are much higher, because it acts more blindly, and losses of 2-3\% are expected, according to experience of operating such PV plants [13]. Compared with efforts in improving inverter efficiency, which add $1-2 \%$ for the new $1500 \mathrm{~V}$ inverters, the loss of $2-3 \%$ just for inefficient ancillary services, while much better solutions could 
be deployed, looks as an old-style thinking of reaching the FCR target, harmful for the RES owner.

We point out that better solutions are those where a battery with its own power-park (inverter) is performing the FCR service for the PV plant, by leaving it working at its higher efficiency. However, this possibility is not envisioned by RfG, which does not consider batteries and ask for the power park of PV to be able to do by their own the service, which blocks complementary solutions. PV inverter with an internal DC bus can cope better with the code, but an additional DC bus is also reducing with some percentages the overall efficiency, thus bringing back as better solution the separate storage for supporting the service for the PV.

\section{FREQUENCY RELATED SUPPORT - RES UNABLE TO DO THE SERVICE, SYSTEM STABILITY ENDANGERED BY RFG DESIGN}

A second aspect related to the frequency control is that RfG requires the availability of the FCR services for 15 to 30 minutes

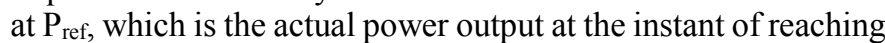
FCR threshold (Article 15, figure 4 and 5). This is for RES-based generators an impossible task by design, because even if RES will ensure the "headroom" of $1-3 \%$ of its momentary peak power, $\mathrm{P}_{\text {ref, }}$ there is no guarantee that RES can provide the $\mathrm{P}_{\text {ref }}$ or $\mathrm{P}_{\text {ref }}-3 \%$ for the entire period of 15-30 minutes. For instance, for the PV units we have a normal increase of $\mathrm{P}_{\text {MAX }}$ in the morning until the midday, case in which the RfG request can be supported, but we have also a normal decrease of $\mathrm{P}_{\text {ref }}$ in the afternoon, which makes impossible to support the FCR required as stated in the RfG. It means that, in the first part of the day, the system is more secure, because RES-based generator is prepared for its own FCR contribution, but in the afternoon this is compromised, because $P_{\text {ref }}$ can decrease more than any $1-3 \%$, thus endangering power system stability through reduced or unpredictable FCR during this period; this situation can be seen like a "RfG bug" by design (the power reduction due to ambient conditions is also mentioned in RfG). Figure 2 shows this situation, in both summer and winter days with sunny situation (PV profile taken from [14]). It is also clear that if a partially sunny day does exist (sun-clouds-sun etc.), the unpredictability to provide appropriate FCR is even higher, making stability during disturbances an even harder to ensure this process. The problem of this unpredictability of the primary energy resource over the 15 to 30 minutes of full active power frequency response is addressed in RfG code at Article 15, 2(d) (v), but the unsolved issue is left open for the TSO decision.

Unpredictability of FCR from wind generation has similar drawbacks (a percentage from $\mathrm{P}_{\text {ref }}$ cannot be guaranteed for FCR over 15 minutes), even if it is more cited as being used in practice.

Based on the above stated facts, one can understand that the main goal of preserving system stability through ancillary services such as FCR (requested for generators type C and D) is now the unpredictability of FCR service provided by RES, which may result in a dangerous situation.

However, if FCR for RES can be performed - as proposed also in section IV, by a separate entity, i.e. storage based powerpark, FCR can be predictable and can be based even on

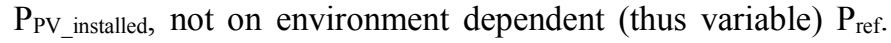

This storage entity providing FCR needs to be recognized in RfG as being logically coupled with the RES; it can be connected to the same connecting point or nearby, solution that can be negotiated with the relevant grid operator. As an option, in [15] it is proposed to connect a storage resource directly to the PV system, which has potential to solve the problem announced above; however, this solution has the disadvantage of requiring an additional DC bus (before the inverter), which makes it more expensive and with lower overall efficiency (two switching blocks in series) than the cluster PV and storage (each having only one switching blocks); such a cluster would operate with complementary functions on the AC side.

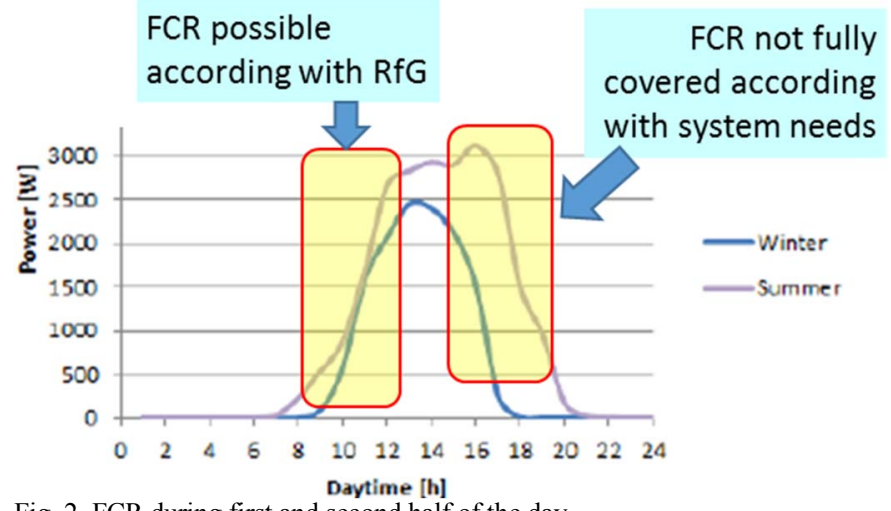

Fig. 2. FCR during first and second half of the day.

Instead of getting total FCR band as a sum of contributions based on percentage of nominal power for classic synchronous power generating modules (which is deterministic) and percentage of fluctuating $\mathrm{P}_{\text {ref }}$ in RES situation (which is stochastic in nature), it is much better to maintain predictable total FCR bands obtained from devices capable to guarantee it (e.g. synchronous generators or batteries). This is also a reason why FCR becomes more and more a paid service based on market auctions and not a necessary condition for connection, as created through the RfG requirements for capabilities. FCR service treated alone, covering duties for other grid-connected generators, is in line with FCR as a paid service, which is better done by specialized resources, as already pointed in [5].

\section{CONCLUSIONS}

The RfG code has been analyzed and different discrepancies from today's trends have been observed. Essential system components such as storage facilities (bivalent productionconsumption behavior) and prosumer (hybrid behavior) are completely disregarded. Moreover, RES technologies are considered to perform ancillary services while these can be provided more efficiently by separate storage facilities. Additionally, the preoccupation of utilities in controlling also small generators (down to $800 \mathrm{~W}$ ), with all the costs incurred for ensuring communication and SCADA integration, without any clear RES behind the meter policy, is making the code difficult to apply and prone to operators' abuse.

The place where it is expected more the energy revolution, the smart grid deployment in low (and partially in medium) voltage network, is also totally neglected. Instead, a full control from utilities becomes a possible mean of operation, contrary to 
modern solutions like hierarchical control empowered at each level, from prosumer, neighborhood and distribution microgrid up to levels where system operator is relevant.

In addition, there is a lack of standardization, e.g., on frequency and ROCOF measurement to be used as reliable inputs for performing services, which may be not available in time with RfG aim for operation.

However, results from EU FP7 and H2020 projects support the modern approach of hierarchical functionality, of microgrids, of empowering the citizen and of improving resilience, while many of them being in severe contradiction with the full control perspective of $\mathrm{RfG}$ with requests of capabilities down to $800 \mathrm{~W}$ installed power. More efforts are needed to harmonize the beneficial aims of these projects and the pan-European energy rules in energy. Fortunately, the member states have a chance to come with the "power to grant derogation" (articles 61-64) and to adapt RfG according to their specificity. It is also a hope that the Winter package will correct substantially the "one way" of thinking and will allow an appropriate balance between the citizen, empowered by the new RES and storage technologies, as well as by the common market for energy and services well harmonized with the pan-European regulations.

\section{ACKNOWLEDGMENT}

This work has been funded by University "Politehnica" of Bucharest, through the "Excellence Research Grants" Program, UPB-GEX, contract number 89/26.09.2016, and by the European Commission through the Horizon 2020 research and innovation programme, under the Storage4Grid project grant agreement No. 731155 and RE-SERVE project grant agreement No. 727481 .

\section{REFERENCES}

[1] Commission Regulation (EU) 2016/631 of 14 April 2016 establishing a network code on requirements for grid connection of generators.

[2] European Commission Winter package, Online: http://europa.eu/rapid/press-release_IP-16-4009_en.htm

[3] European $7^{\text {th }}$ Frame Project "e-Highway 2050", Deliverable "D3.1 Technology assessment from 2030 to 2050". On-line: http://www.ehighway2050.eu/fileadmin/documents/Results/D3/report CAES.pdf
[4] S. Mahapatra, "Lowest-Ever Solar Price Bid (2.42 $₫ / \mathrm{kWh})$ Dropped In Abu Dhabi By JinkoSolar \& Marubeni Score”, CleanTechies, September 20, 2016. On-line: http://cleantechies.com/2016/09/20/jinkosolarmarubeni-score-lowest-ever-solar-pv-at-us $\% \mathrm{C} 2 \% \mathrm{~A} 22-42 \mathrm{kwh}$-in-abudhabi/

[5] D. Pickup, "Large-scale storage gains toehold in the UK", February 22, 2017. On-line: http://www.energy-storage.news/blogs/large-scalestorage-gains-toehold-in-the-uk

[6] D. Schweer, A. Maaz and A. Moser, "Optimization of frequency containment reserve provision in M5BAT hybrid battery storage", 2016 13th International Conference on the European Energy Market (EEM), Porto, 2016, pp. 1-5.

[7] D. Steber, P. Bazan and R. German, "SWARM - strategies for providing frequency containment reserve power with a distributed battery storage system", 2016 IEEE International Energy Conference (ENERGYCON), Leuven, 2016, pp. 1-6.

[8] J. Pyper, "Tesla, Greensmith, AES Deploy Aliso Canyon Battery Storage in Record Time", January 31, $2017 . \quad$ On-line: https://www.greentechmedia.com/articles/read/aliso-canyon-emergencybatteries-officially-up-and-running-from-tesla-green

[9] P. Polityuk, O. Vukmanovic, S. Jewkes, "Ukraine's power outage was a cyber attack: Ukrenergo", January 18, $2017 . \quad$ On-line: http://www.reuters.com/article/us-ukraine-cyber-attack-energyidUSKBN1521BA

[10] N.W. Miller, M. Shao, S. Venkataraman, "California ISO (CAISO) Frequency response study”, GE Energy Report, November 9, 2011.

[11] ENTSO-E, "Network Code on Load-Frequency Control and Reserves". Supporting document, June 28, 2013.

[12] Requirements and tests for systems intended to avoid the energy transmission to the distribution network (Requisitos y ensayos para sistemas que eviten el vertido de energía a la red de distribución), UNE 217001:2015 IN, July 10, 2015. (in Spanish)

[13] F. Spertino, A. Ciocia, P. Di Leo, R. Tommasini, I. Berardone, M. Corrad, A. Infuso and M. Paggi, "A power and energy procedure in operating photovoltaic systems to quantify the losses according to the causes", Solar Energy, vol. 118, pp. 313-326, 2015.

[14] R. Velik, "Battery Storage versus Neighborhood Energy Exchange to Maximize Local Photovoltaics Energy Consumption in Grid-Connected Residential Neighbourhoods", International Journal of Advanced Renewable Energy Research, vol.2, no.6, 2013.

[15] J. C. Hernandez, F. Sanchez-Sutil and P. G. Bueno, "Large photovoltaic systems providing frequency containment reserves", 2016 IEEE PES Asia-Pacific Power and Energy Engineering Conference (APPEEC), Xi'an, 2016, pp. 1589-1593. 